\title{
Evaluating freight forwarders in the air cargo industry
}

\author{
Elif B. Kiziltas, Zeynep Sener, Mehtap Dursun \\ Industrial Engineering Department, Galatasaray University, Turkey \\ Received: July 20, 2021. Revised: November 10, 2021. Accepted: December 5, 2021. Published: December 29, 2021.
}

\begin{abstract}
Freight forwarders are of great importance in the air cargo industry. As the cargo revenue constitutes an important source for airline companies, the evaluation of freight forwarders is vital for airlines' success. This study employs DEMATEL method in order to prioritize the determined criteria for evaluating freight forwarders from the point of view of an airline. The calculated importance weights are used in an illustrative problem where the ranking of freight forwarders are obtained by employing the simple additive weighting method.
\end{abstract}

Keywords-Air logistics, freight forwarder evaluation, DEMATEL, multiple criteria decision making.

\section{INTRODUCTION}

A IR freight transportation has been of great importance for world trade, in recent decades. Shipping of goods by air cargo is faster, more reliable and safer than other modes of transport.

Although the cargo volume carrying by air transport constitutes $1 \%$ of all commodities by weight, it corresponds to $35 \%$ of the world trade by value [1]. An annual growth rate of $4 \%$ is forecast for the air cargo market over the next 20 years [1].

The Covid-19 crisis, which started in 2019 and is still ongoing, had serious negative effects on every sector. Despite the pandemic; the operations of the air cargo sector continue even with limited capacity. Air cargo plays a crucial role especially in the transportation of medical equipments, medicines, and vaccines.

Air cargo transport differs from air passenger transport in terms of uncertainty, complexity and flexibility issues [2].

As the revenue obtained by air freight transport constitutes an important source for airline companies, a number of researches addressing air cargo problems can be found in the literature. Feng et al. [2] presented a review of studies on air cargo operations.

Air cargo transportation consists of many complex processes with the participation of more than one party. The main actors of air cargo operations are shippers, freight forwarders, road transporters, airlines, and receivers. Air freight forwarders are intermediaries between shippers and carriers; they manage the shipping process in a timely, safe and cost-effective manner on behalf of shippers [3]. As the cargo revenue of airline companies mostly depends on forwarders, the evaluation of freight forwarders is critical for carrier airlines.

This paper proposes a Decision Making Trial and Evaluation Laboratory (DEMATEL) approach to determine and prioritize the criteria for air freight forwarders from the airline's perspective. The evaluation criteria are defined in the following section. Section III presents the steps of the DEMATEL method. In Section IV, the applicability of the proposed approach is illustrated by an illustrative problem where the freight forwarders are ranked with the simple additive weighting (SAW) method. Finally, conclusions are provided in the last section.

\section{CRITERIA FOR FREIGHT FORWARDER EVALUATION}

The forwarders are generally considered as third-party logistics (3PL) service provider companies. The evaluation, ranking and selection of $3 \mathrm{PL}$ companies were vastly examined in the literature.

Aguezzoul [4] presented a detailed literature review on criteria and methods about third-party logistics selection problem. The study identified 11 key 3PL selection criteria, namely; cost, relationship, services, quality, information and equipment system, flexibility, delivery, professionalism, financial position, location, and reputation.

Skender et al. [5] presented differences between 3PL companies and freight forwarders. In the air cargo operations' literature, only a few of the research papers treated freight forwarder related issues [2].

Feng et al. [6] proposed a distributional robust optimization model for selecting freight forwarders under air cargo supply disruptions. The proposed approach can be used by airlines to solve freight forwarder selection problems.

Feng and Lai [7], using a strategic freight forwarder selection problem as a backdrop, presented a multi attribute decision making approach which integrates aspirations with the utility theory.

Zhang et al. [8] developed a deviation modeling method to deal with the heterogeneous multiple criteria group decision making problems with incomplete weight 
information. Their proposed method is illustrated by using the selection problem of strategic freight forwarder of China Southern Airlines.

With its need to trade-off multiple criteria, air freight forwarder evaluation from airline's perspective is a complex multiple criteria decision making (MCDM) problem.

In this paper, in order to define freight forwarder evaluation criteria, a literature survey is conducted. The criteria used in previous research papers $[4,6,7,8]$ are listed and reformulated by air cargo experts. The criteria obtained as a result of this work are supply quantity, supply stability, no-show rate, financial power, technological capability. The five criteria are provided in Table I.

Table I. Evaluation criteria

\begin{tabular}{|l|l|}
\hline Criterion $1(\mathrm{C} 1)$ & supply quantity \\
\hline Criterion $2(\mathrm{C} 2)$ & supply stability \\
\hline Criterion $3(\mathrm{C} 3)$ & no-show rate \\
\hline Criterion $4(\mathrm{C} 4)$ & financial power \\
\hline Criterion 5 (C5) & technological capability \\
\hline
\end{tabular}

\section{DEMATEL METHOD}

The DEMATEL methodology [9] developed by the Science and Human Affairs Program of the Battelle Memorial Institute of Geneva between 1972 and 1976 [10].

Based on the graph theory, the DEMATEL method can divide multiple factors into a cause-effect group and it enables the decision maker to visualize influences between criteria with a network relationship map [11].

The method begins by generating the initial direct influence matrix. The elements $a_{\mathrm{ij}}$ of the matrix $A$ represent the direct influence of each factor $i$ exerts on each factor $j$, evaluated by a decision maker. The matrix $A$ is normalized by using (1) and it is named as the matrix $D[10,11,12]$.

$D=\mathrm{s} . A$,

where

$$
s=\min \left\lfloor\frac{1}{\max _{1 \leq i \leq n} \sum_{j=1}^{n}\left|a_{i j}\right|}, \frac{1}{\max _{1 \leq i \leq n} \sum_{i=1}^{n}\left|a_{i j}\right|}\right\rfloor
$$

The total relation matrix $T$ is defined as $T=D(I-D)^{-1}$ where $I$ is the identity matrix.

Define $r$ and $c$ be $n \times 1$ and $1 \times n$ vectors representing the sum of rows and sum of columns of the total relation matrix $T$, respectively. Suppose $r_{\mathrm{i}}$ be the sum of $i^{\text {th }}$ row in matrix
$T$, then $r_{\mathrm{i}}$ shows both direct and indirect effects given by factor $i$ to the other factors. If $c_{\mathrm{j}}$ denotes the sum of $j^{\text {th }}$ column in matrix $\mathrm{T}$, then $c_{\mathrm{j}}$ shows both direct and indirect effects by factor $j$ from the other factors [11].

When solving a decision making problem, the use of DEMATEL method enables also the decision maker to obtain the importance weights of the criteria, in addition to its ability to visualize the interactions between them.

The degree of importance for a factor $i$ is considered as equals to the sum $\left(r_{\mathrm{i}}+c_{\mathrm{j}}\right)$ when $j=i[11,13]$. A network relationship map which explains the structural relations among factors can be obtained by setting up a threshold value which is determined by the decision makers [11].

Additionally, the difference $\left(r_{\mathrm{i}}-c_{\mathrm{j}}\right)$ represents the net effect that factor $i$ contributes to the system. A factor $i$ is a net causer if $\left(r_{\mathrm{i}}-c_{\mathrm{j}}\right)$ is positive, and when $\left(r_{\mathrm{i}}-c_{\mathrm{j}}\right)$ is negative, factor $i$ is a net receiver [11].

\section{ILLUSTRATIVE APPLICATION}

An air cargo carrier needs to carefully evaluate its freight forwarders in order to establish a system in which premium and incentive levels are effectively determined.

This study proposes to employ DEMATEL method to prioritize the criteria for evaluating air freight forwarders from the point of view of an airline company. The evaluation criteria are summarized in Table I.

In order to apply DEMATEL method, a team of two air cargo experts indicates the influence of each criterion $i$ exerts on each factor $j$ of the others, using an integer scale [10] which is going from " 0 " (no influence) to " 4 " (extreme strong influence) represented in Table II.

Table II. Influence degrees

\begin{tabular}{|l|l|}
\hline No influence & 0 \\
\hline Low influence & 1 \\
\hline Moderate influence & 2 \\
\hline Strong influence & 3 \\
\hline Extreme strong influence & 4 \\
\hline
\end{tabular}

Each expert reflects her/his opinion in her/his own influence matrix. The matrix of the first expert is given in Table III and the matrix of the second expert is shown in Table IV.

Table III. Influence matrix of expert1

\begin{tabular}{|c|c|c|c|c|c|}
\cline { 2 - 6 } \multicolumn{1}{c|}{} & C1 & C2 & C3 & C4 & C5 \\
\hline C1 & 0 & 3 & 2 & 2 & 2 \\
\hline C2 & 3 & 0 & 2 & 2 & 1 \\
\hline
\end{tabular}




\begin{tabular}{|l|l|l|l|l|l|}
\hline C3 & 2 & 2 & 0 & 1 & 1 \\
\hline C4 & 1 & 1 & 1 & 0 & 4 \\
\hline C5 & 2 & 2 & 3 & 1 & 0 \\
\hline
\end{tabular}

Table IV. Influence matrix of expert2

\begin{tabular}{|c|c|c|c|c|c|}
\cline { 2 - 6 } \multicolumn{1}{c|}{} & $\mathrm{C} 1$ & $\mathrm{C} 2$ & $\mathrm{C} 3$ & $\mathrm{C} 4$ & $\mathrm{C} 5$ \\
\hline $\mathrm{C} 1$ & 0 & 3 & 2 & 2 & 2 \\
\hline $\mathrm{C} 2$ & 2 & 0 & 2 & 2 & 1 \\
\hline C3 & 2 & 2 & 0 & 1 & 0 \\
\hline C4 & 1 & 1 & 1 & 0 & 3 \\
\hline C5 & 1 & 2 & 3 & 1 & 0 \\
\hline
\end{tabular}

The average matrix, shown in Table $\mathrm{V}$, is obtained by computing the average of the influence matrices which are deducted from pairwise comparisons made by two experts.

Table V. The average matrix

\begin{tabular}{|l|c|c|c|c|c|}
\cline { 2 - 6 } \multicolumn{1}{c|}{} & C1 & C2 & C3 & C4 & C5 \\
\hline C1 & 0 & 3 & 2 & 2 & 2 \\
\hline C2 & 2.5 & 0 & 2 & 2 & 1 \\
\hline C3 & 2 & 2 & 0 & 1 & 0.5 \\
\hline C4 & 1 & 1 & 1 & 0 & 3.5 \\
\hline C5 & 1.5 & 2 & 3 & 1 & 0 \\
\hline
\end{tabular}

The average matrix which is normalized using (1) and (2), is given in Table VI.

Table VI. Normalized initial direct influence matrix

\begin{tabular}{|l|c|c|c|c|c|}
\cline { 2 - 6 } \multicolumn{1}{c|}{} & C1 & C2 & C3 & C4 & C5 \\
\hline C1 & 0 & 0.333 & 0.222 & 0.222 & 0.222 \\
\hline C2 & 0.278 & 0 & 0.222 & 0.222 & 0.111 \\
\hline C3 & 0.222 & 0.222 & 0 & 0.111 & 0.056 \\
\hline C4 & 0.111 & 0.111 & 0.111 & 0 & 0.389 \\
\hline C5 & 0.167 & 0.222 & 0.333 & 0.111 & 0 \\
\hline
\end{tabular}

An identity matrix $I(5 \times 5)$ shown in Table VII is required to calculate the total relation matrix.

Table VII. Identity matrix

\begin{tabular}{|l|l|l|l|l|}
\hline 1 & 0 & 0 & 0 & 0 \\
\hline 0 & 1 & 0 & 0 & 0 \\
\hline 0 & 0 & 1 & 0 & 0 \\
\hline 0 & 0 & 0 & 1 & 0 \\
\hline 0 & 0 & 0 & 0 & 1 \\
\hline
\end{tabular}

Finally, the total relation matrix, which is defined as $T=D(I-D)^{-1}$ is calculated. Table VIII shows the matrix $T$.

Table VIII. Total relation matrix

\begin{tabular}{|c|c|c|c|c|c|}
\cline { 2 - 6 } \multicolumn{1}{c|}{} & C1 & C2 & C3 & C4 & C5 \\
\hline C1 & 0.804 & 1.140 & 1.060 & 0.875 & 0.927 \\
\hline C2 & 0.910 & 0.765 & 0.933 & 0.782 & 0.754 \\
\hline C3 & 0.727 & 0.783 & 0.586 & 0.574 & 0.560 \\
\hline C4 & 0.703 & 0.771 & 0.787 & 0.512 & 0.873 \\
\hline C5 & 0.823 & 0.929 & 1.000 & 0.679 & 0.606 \\
\hline
\end{tabular}

The difference $\left(r_{\mathrm{i}}-c_{\mathrm{j}}\right)$ represents the net effect that factor $i$ contributes to the system. According to Table IX, the criteria $\mathrm{C} 1$ (quantity supplied by the freight forwarder), $\mathrm{C} 4$ (financial power of the freight forwarder) and $\mathrm{C} 5$ (technological capability of the freight forwarder) are net causer and the criteria $\mathrm{C} 2$ (supply stability of the freight forwarder) and $\mathrm{C} 3$ (no-show) are net receiver.

Table IX. Difference (rows-columns) for each criterion

\begin{tabular}{|l|c|}
\cline { 2 - 2 } \multicolumn{1}{c|}{} & $\begin{array}{c}\text { difference } \\
\left(r_{\mathrm{i}}-c_{\mathrm{j}}\right)\end{array}$ \\
\hline C1 & 0.839 \\
\hline C2 & -0.240 \\
\hline C3 & -1.140 \\
\hline C4 & 0.224 \\
\hline C5 & 0.317 \\
\hline
\end{tabular}

The sum of rows and sum of columns of the total relation matrix are calculated and Table X shows the sum $\left(r_{\mathrm{i}}+c_{\mathrm{j}}\right)$ when $j=i$.

Table X. Sum (rows+columns) for each criterion

\begin{tabular}{|l|c|}
\cline { 2 - 2 } \multicolumn{1}{c|}{} & $\begin{array}{c}\text { sum } \\
\left(r_{\mathrm{i}}+c_{\mathrm{j}}\right)\end{array}$ \\
\hline C1 & 8.774 \\
\hline C2 & 8.534 \\
\hline C3 & 7.596 \\
\hline C4 & 7.068 \\
\hline C5 & 7.758 \\
\hline
\end{tabular}

As mentioned in Section III, the degree of importance for a factor $i$ is considered as equals to the sum $\left(r_{\mathrm{i}}+c_{\mathrm{j}}\right)$ when $j=i$. The sum $\left(r_{\mathrm{i}}+c_{\mathrm{j}}\right)$ for each criteria are normalized and the normalized weights of the criteria are given in Table XI.

Table XI. Weights of criteria

\begin{tabular}{|l|l|}
\hline C1 & 0.221 \\
\hline C2 & 0.215 \\
\hline C3 & 0.191 \\
\hline C4 & 0.178 \\
\hline C5 & 0.195 \\
\hline
\end{tabular}


According to Table XI, the most important criterion for evaluating freight forwarders is the supply quantity. The supply stability and the technological capability of an air freight forwarder are the other critical factors.

This paper uses a hypothetical data set to assess the ranking of the freight forwarders. The performance values of the freight forwarders with respect to each evaluation criterion are provided in Table XII. Forwarders' performance is scaled from 1 to 5 , with 1 indicating very low performance and 5 indicating very high performance.

Table XII. Performance assessment of freight forwarders

\begin{tabular}{|l|c|c|c|c|c|}
\cline { 2 - 6 } \multicolumn{1}{c|}{} & C1 & C2 & C3 & C4 & C5 \\
\hline FF1 & 4 & 3 & 2 & 5 & 2 \\
\hline FF2 & 4 & 5 & 4 & 2 & 3 \\
\hline FF3 & 5 & 4 & 3 & 4 & 5 \\
\hline FF4 & 4 & 4 & 4 & 3 & 3 \\
\hline FF5 & 2 & 4 & 4 & 3 & 4 \\
\hline FF6 & 5 & 3 & 4 & 3 & 2 \\
\hline FF7 & 3 & 2 & 3 & 5 & 1 \\
\hline
\end{tabular}

The simple additive weighting method is employed to obtain a final score for each freight forwarder using the importance weights of evaluation criteria and the assessment matrix. The evaluation scores are calculated from the performance values multiplied by the weights of criteria. As an example, the evaluation score for the first freight forwarder (FF1) is equals to:

\section{$4 * 0.221+3 * 0.215+2 * 0.191+5 * 0.178+2 * 0.195=3.190$}

The final scores obtained for seven freight forwarders are given in Table XIII.

Table XIII. The evaluation scores

\begin{tabular}{|l|c|}
\cline { 2 - 2 } \multicolumn{1}{c|}{} & $\begin{array}{c}\text { evaluation } \\
\text { score }\end{array}$ \\
\hline FF1 & 3.190 \\
\hline FF2 & 3.664 \\
\hline FF3 & 4.225 \\
\hline FF4 & 3.627 \\
\hline FF5 & 3.380 \\
\hline FF6 & 3.438 \\
\hline FF7 & 2.750 \\
\hline
\end{tabular}

The ranking of the freight forwarders regarding to evaluation scores is provided in Table XIV.

Table XIV. The ranking of freight forwarders

\begin{tabular}{|c|c|}
\cline { 2 - 2 } \multicolumn{1}{c|}{} & $\begin{array}{c}\text { evaluation } \\
\text { score }\end{array}$ \\
\hline FF3 & 4.225 \\
\hline
\end{tabular}

\begin{tabular}{|l|l|}
\hline FF2 & 3.664 \\
\hline FF4 & 3.627 \\
\hline FF6 & 3.438 \\
\hline FF5 & 3.380 \\
\hline FF1 & 3.190 \\
\hline FF7 & 2.750 \\
\hline
\end{tabular}

The carrier company can use the performance ranking to determine levels of premium and incentives to be offered to freight forwarders.

\section{CONCLUSION}

As the cargo revenue plays an important role in airline companies' profitability, the evaluation of freight forwarders is crucial for carriers. An airline needs to carefully evaluate its freight forwarders in order to establish a system in which premium and incentive levels are effectively determined.

In this paper, a literature survey is conducted to define freight forwarder evaluation criteria. The criteria employed in previous research papers are listed and reformulated by air cargo experts. The five criteria obtained as a result of this work are supply quantity, supply stability, no-show rate, financial power, technological capability.

This paper employs the DEMATEL method to prioritize the determined evaluation criteria for air freight forwarders from the airline's perspective. Then, a hypothetical example is given to illustrate the utilization of the weights of criteria in the air forwarders' evaluation process. Using the calculated importance weights, the simple additive weighting method is applied in the case problem to obtain a final score for each freight forwarder.

Future research will focus on modeling a system which evaluates air forwarders for an airline company and sets the levels of premium and incentives given to them. The modeling approach to be developed will be dealing qualitative and quantitative performance assessments of real-world problems.

\section{REFERENCES}

[1] Boeing, Commercial Market Outlook 2020-2039, Available: http:// http://www.boeing.com/resources/boeingdotcom/market/assets/do wnloads/2020_CMO_PDF_Download.pdf

[2] B. Feng, Y. Li, and Z.-J. M. Shen, "Air cargo operations: literaturre review and comparison with practices", Transportation Research Part C, vol. 56, pp. 263-280, 2015.

[3] W. He, L. C. Leung, Y. V. Hui, and G. Chen, "An air freight forwarder's resource planning and revenue management", Journal of the Operational Research Society, vol. 70, no. 2, pp. 294-309, 2019.

[4] A. Aguezzoul, "Third-party logistics selection problem: a literature review on criteria and methods", Omega, vol. 49, pp. 69-78, 2014.

[5] H. P. Skender, A. Host, M. Nuhanovic, "The role of logistics service providers in international trade", Business Logistics in Modern Management, vol. 16, pp. 21-37, 2016.

[6] B. Feng, Z. Jiang, and F. Lai, "Robust approach for air cargo freight forwarder selection under disruption", Annals of Operations Reseach, vol. 291, pp. 339-360, 2020.

[7] B. Feng and F. Lai, "Multi-attribute group decision making with aspirations: a case study", Omega, vol. 44, pp. 136-147, 2014. 
[8] X. Zhang, Z. Xu, and H. Wang, "Heterogeneous multiple criteria group decision making with incomplete weight information: a deviation modeling approach", Information Fusion, vol. 25, pp. 4962, 2015.

[9] E. Fontela and A. Gobus, "The DEMATEL observer", Battelle Geneva Research Center, 1976.

[10] G.-H. Tzeng, W.-H. Chen, R. Yu, and M.-L. Shih, "Fuzzy decision maps: a generalization of the DEMATEL methods", Soft Computing, vol. 14, pp. 1141-1150, 2010.

[11] J. L. Yang and G.-H. Tzeng, "An integrated MCDM technique combined with DEMATEL for a novel cluster-weighted with ANP method", Expert Systems with Applications, vol. 38, pp. 1417- 1424, 2011.

[12] C.-H. Hsu, F.-K. Wang, and G.-H. Tzeng, "The best vendor selection for conducting the recycled material based on a hybrid MCDM model combining DANP with VIKOR", Resources, Conservation and Recycling, vol. 66, pp.95-111, 2012.

[13] C.-H. Wang and J.-N. Chen, "Using quality function deployment for collaborative product design and optimal selection of module mix", Computers \& Industrial Engineering, vol. 63, pp. 1030-1037, 2012.

\section{Creative Commons Attribution License 4.0 (Attribution 4.0 International, CC BY 4.0)}

This article is published under the terms of the Creative Commons Attribution License 4.0

https://creativecommons.org/licenses/by/4.0/deed.en_US 